\title{
Thoughts on NGS, alternative splicing and what we still need to know
}

\author{
KRISTEN W. LYNCH \\ Department of Biochemistry and Biophysics, University of Pennsylvania Perelman School of Medicine, Philadelphia, Pennsylvania 19104-6059, USA
}

Twenty-two years ago I attended my first scientific meeting: the 1993 Cold Spring Harbor RNA meeting. Although initially overwhelmed by not being able to keep up with the seemingly endless knowledge of others, I left the meeting both having fallen in love with the field of RNA and having met many people who continue to be some of my closest friends and colleagues. However, what I didn't realize at the time was that the most important thing to happen at that meeting was not the 2nd-year grad student poster I presented, or even the shaping of my career path, but rather the formalizing of the formation of the RNA Society. For though I was just learning these lessons, many others already knew that RNA is sufficiently exciting and full of unexplored mysteries to warrant a lifetime of study, and that research is both more enjoyable and more efficient when done in the context of a community. The founders of the Society also recognized the importance of having a journal to encourage and promote the publication of progress made on the study of RNA, and so this journal aptly named $R N A$ was born two years later.

Excitingly, the assumption made 22 years ago that RNA would continue to interest and amaze us could not have been more accurate. These past two decades have witnessed an explosion in our knowledge of almost all aspects of RNA, including the achievement of high resolution structures of the ribosome, the recognition that alternative splicing is the rule not the exception, and the discovery that our cells are full of countless non-coding RNAs that play roles in almost every aspect of gene regulation and cellular function. Whereas the study of RNA used to be confined to a relative few RNA-centric research groups, now seemingly everyone is interested and there is hardly a laboratory around in which someone isn't carrying out some study related in some way to RNA. As one of my senior colleagues once quipped "we [outside the RNA field] used to think of RNA like we think of water-present and essential, but not really that interesting. Now we know better."

Corresponding author: klync@mail.med.upenn.edu

Article and publication date are at http://www.rnajournal.org/cgi/doi/10. 1261/rna.050419.115. Freely available online through the RNA Open Access option.
Much of the recent explosion in our knowledge of RNA can be traced to the development of genomic profiling methods, starting with microarrays and then taking off exponentially with the advent of next generation sequencing (NGS). The NGS methods, in particular, have allowed for the identification of RNA populations we never guessed existed: miRNAs, lncRNAs, lincRNAs, piRNAs, circRNA, to name but a few. The discoveries of these classes of RNA have opened exciting new areas of biology and have captured the attention of the science community broadly. Closer to my own area of research, NGS methods have also revealed there to be much greater variation and regulation in RNA processing events than previously imagined. For example, when I started in the field of splicing regulation, leading reviews predicted that alternative splicing might occur in as much as 5\% of human genes. Current estimates are now that all but $5 \%$ of human genes undergo some form of alternative splicing. While all of this new insight has been tremendously exciting, the speed of discovery has left many gaps and holes in its wake. As we move into the post-NGS era I see two major understudied areas, at least with regards to alternative splicing, that represent the greatest challenge and the greatest opportunity for impact in the decade ahead: understanding the functional consequence of alternative splicing and determining the molecular mechanism(s) by which the spliceosome activity is directed to preferentially form one splice isoform over another.

The discovery that virtually all mammalian genes are alternatively spliced in some cell type or condition is of course extremely exciting for those of us interested in splicing regulation-and is a compelling statistic to cite in publications or grants to underscore the importance of studying this process. Yet the fact remains the functional relevance of alternative splicing has only been demonstrated for an exceedingly small fraction of these cases. To truly appreciate the full impact of alternative splicing on biologic processes, and argue against those who wonder if it might all be "noise," we need to do better. The question is how to achieve this goal. It is clearly

(C) 2015 Lynch This article, published in $R N A$, is available under a Creative Commons License (Attribution-NonCommercial 4.0 International), as described at http://creativecommons.org/licenses/by-nc/4.0/. 
impractical for any single research group to individually test the differential function of all known protein isoforms. Even if one was to restrict study to a particular set of genes (e.g., those encoding transcription factors, MAP kinases, SR proteins, etc), the number of reported isoforms and number of potential functional consequences would make this a foolhardy fishing expedition if done on a case-by-case basis. Perhaps we should be asking ourselves whether there are more high-throughput methods for studying the functional impact of alternative splicing. Conceivably something akin to a genetic screen could be developed using pools of exonspecific siRNAs, or splice-blocking antisense oligonucleotides to uncover the functional impact of differential expression of one gene, or a family of genes. The establishment of such a method could potentially have as much impact on the field of splicing as has NGS sequencing.

Alternatively, revelations regarding the functional consequence of alternative splicing may best come from outside the RNA community-from those studying various individual genes or cellular processes who have come across an interesting isoform. Particularly as the broader scientific community is increasingly aware of the breadth of RNAbased gene regulation - and is looking out for it - I envision that we will increasingly see studies highlighting differential isoform function coming from all corners of the scientific community. This is something we as "RNA people" should encourage and support. Some of my most fascinating collaborations have come from being contacted for help by researchers at my university who have no experience with RNA but have come across an interesting spliced isoform in some disease, comparative tissue study or functional screen. These collaborations have given me the opportunity to be involved in some tremendously exciting science well outside of areas in which I ever thought I would be involved, and has led to insight on the functional consequence of splicing that my group could never have achieved on our own.

In addition to gaining a better understanding of the functional consequence of the breadth of alternative splicing detected by NGS, moving forward we also need to have a clearer picture of how this is all achieved. As a field, we know the spliceosome is a complex, dynamic machine, and over the past decade we have learned that virtually all steps in the assembly of the catalytic complex can be regulated. But exactly how various known enhancer and silencer proteins direct the activity of the spliceosome remain obscure. The first described models of blocking or recruitment certainly account for many instances of alternative splicing, but even here our knowledge is limited. What is actually being recruited or blocked? What are the specifics of the protein-protein or protein-RNA interactions through which this is mediated? Do regulatory proteins ever induce allosteric changes within the spliceosome which affect long-range outcomes? While our current "factor-X-controls-exon-Y" level of understanding of regulatory mechanism has been sufficient to answer some questions in the field, and even guide some therapeutic intervention in splicing, we can't truly say we understand splicing regulation until we have a much deeper grasp of the molecular details of this process.

Historically, a major road block to deep insight into the mechanisms of splicing regulation has been the limited understanding we have had of the spliceosome structure in general. Most of us in the splicing field have experienced "ribosome envy" at some point-a deep longing to work on a system with greater than oval-and-line resolution. The crystal structures of the ribosome that have emerged over the past 20 years have completely transformed the ability of ribosome biochemists to design and interpret mechanistic experiments. Meanwhile, those of us fascinated by the regulation of spliceosome assembly are often still trying to figure out which of the hundred-plus proteins within the growing spliceosome are even in close proximity to each other. That is not to say that we haven't made much progress over the past 20 some years. We do now have high resolution structures of a few spliceosome subunits, biochemical and genetic experiments have defined many inter- and intra-molecular interactions within the spliceosome, and we all cheer on Reinhard Luhrmann and his group each time they get a step closer to a crystal of the enzymatic complex. Indeed, it would seem the splicing field is on the cusp of our own high-resolution revolution. The next ten years are likely to be a time of tremendous excitement and progress ushered in by both atomic-level views of spliceosomal complexes, and an influx of corresponding higher-sensitivity and higher-precision biochemical methods to interrogate transitions between static structures. All of this will have fundamental impact on our ability to determine how splicing decisions are achieved and I, for one, can't wait to see what we will learn.

Importantly, none of the future challenges laid out above can be met by a single lab in isolation. One of the aspects of the RNA community I have most enjoyed through the years has been the camaraderie I have experienced. People who could have been competitors have most often instead been colleagues, sharing results and giving advice when I've hit roadblocks. As a community we all benefit from this atmosphere, as work doesn't get duplicated but rather we build on each other's successes thereby achieving more rapid progress toward the goals we all seek. As our community grows, and draws in those from more scientifically diverse backgrounds, we must keep this sense of welcome and cooperation. We will all win from the discoveries guaranteed to emerge as we work together in the years ahead. 

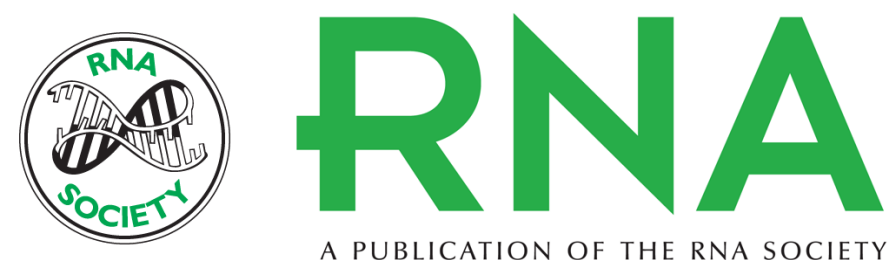

A PUBLICATION OF THE RNA SOCIETY

\section{Thoughts on NGS, alternative splicing and what we still need to know}

Kristen W. Lynch

RNA 2015 21: 683-684

Open Access Freely available online through the RNA Open Access option.

Creative This article, published in RNA, is available under a Creative Commons License

Commons (Attribution-NonCommercial 4.0 International), as described at

License http://creativecommons.org/licenses/by-nc/4.0/.

Email Alerting Receive free email alerts when new articles cite this article - sign up in the box at the Service top right corner of the article or click here.

To subscribe to $R N A$ go to:

http://rnajournal.cshlp.org/subscriptions

(C) 2015 Lynch; Published by Cold Spring Harbor Laboratory Press for the RNA Society 